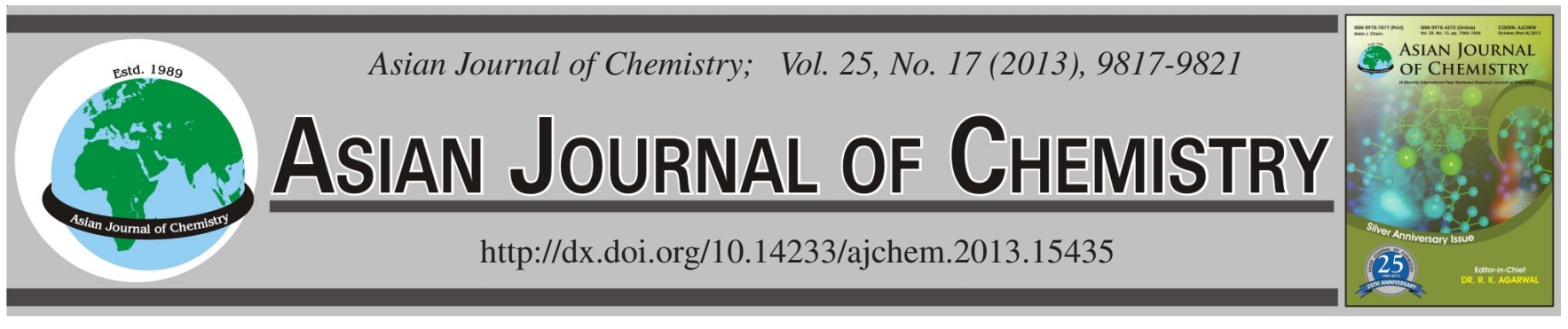

\title{
Rheological Behaviour of Chitosan-Starch Solution
}

\author{
VIRPAL Singh and Kamlesh Kumari"
}

Department of Chemical Technology, Sant Longowal Institute of Engineering and Technology, Longowal-148 106, India

*Corresponding author: E-mail: kamlesh213@yahoo.co.in

(Received: 6 March 2013;

Accepted: 23 October 2013)

AJC-14282

Blends of chitosan $(\mathrm{Ch})$ and starch $(\mathrm{St})$ in different proportions, considering chitosan as a main component were prepared. Rheological
properties of blends such as viscosity and shear stress were investigated as a function of shear rate using Brookfield digital viscometer.
The influence of shear rate and polymer concentration has been analyzed. The chitosan-starch solution showed a non-Newtonian flow
behaviour. The solution properties such as density and refractive index were also measured.
Key Words: Rheology, Shear stress, Shear rate, Flow behaviour index, Density, Refractive index.

\section{INTRODUCTION}

Polymer blends are a class of materials that has received an increasing interest over past few decades. This is due to the fact that such materials possess improved physio-chemical properties and are more suitable for industrial applications as compared to their individual components. Polymer blends can be tailor made to maintain specific properties, which are affected by the interaction i.e., compatibility among the individual polymer components selected for blends ${ }^{1,2}$. Blending of natural polymers is advantageous to obtain new materials without sacrificing their natural properties. Among the natural polymers chitosan occupies special position due to its biodegradable and bio-absorbable properties. Chitosan is a modified natural carbohydrate polymer prepared by the partial $\mathrm{N}$ deacetylation of chitin. Chitin is a nitrogeneous polysaccharides (combination of sugar and protein), abundantly available in natural found in the exoskeletons of crustacean like shrimp, crabs, lobster and other shellfish ${ }^{3-5}$. Chitosan is a linear polysaccharide which consists of 2 -amino-2-deoxy- $\beta$-D-glucopyranose and 2 -acetamido-2-deoxy- $\beta$-D-glucopyranose. Unique properties of chitosan such as bioactivity, biocompatibility and biodegradability have resulted in an increasing interest of its investigation and application ${ }^{6}$. The hydrophilicity of chitosan due to amine functionality in most repeat units makes the chitosan soluble in dilute $\operatorname{acid}^{7}$. The properties of chitosan depends on degree of acetylation ${ }^{8}, \mathrm{pH}^{9,10}$, ionic strength ${ }^{9}$, concentration $^{11}$, temperature ${ }^{12}$, acid concentration ${ }^{13}$, type of $\operatorname{acid}^{14}$ and distribution of acetyl groups along the chain ${ }^{15-16}$. Chitosan is evaluated for various uses in the food, medical, pharmaceutical, agricultural and chemical industries because of its nontoxic, biocompatible, mucoadhesive and biodegradable properties ${ }^{17,18}$. The structure of chitosan is shown in Fig. 1.

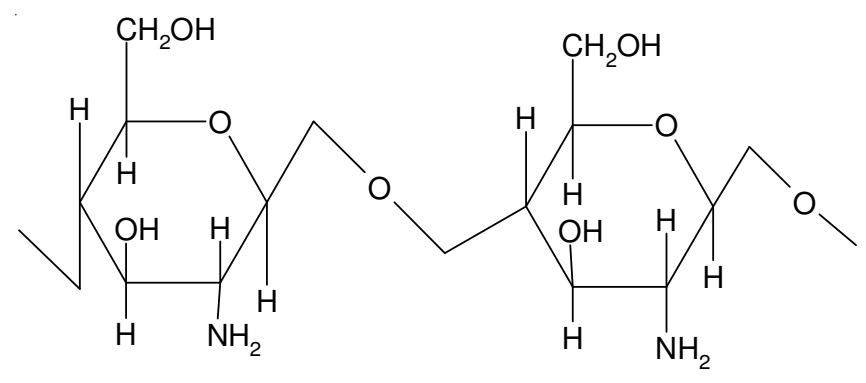

Fig. 1. Chemical structure of chitosan

Starch is biodegradable and naturally metabolized by human body. Starch is mainly composed of two homopolymers of D-glucose-amylose is mostly linear $\alpha$-D $(1,4)$-glucan and amylopectin is branched, having the backbone structure as amylose but with many $\alpha-1,6$ linked branch points. Starch has different proportions of amylose and amylopectin ranging from 10-20\% amylose and 80-90\% amylopectin depending on source. Starch has been applied in the fields of agriculture, medicine, etc. Starch based blend materials do not have good mechanical properties that hinder its application ${ }^{19,20}$. The structure of starch is shown in Fig. 2(a-b).

The measurement of density and refractive index are necessary to study the physico-chemical measurements of chitosan solution $^{21}$. Blending is a method to improve the properties of polymer materials. The miscibility of chitosan blends with hydrophilic polymers: chitosan/polyvinyl alcohol, chitosan/ polyvinylpyrrolidone and chitosan/polyethylene oxide were 


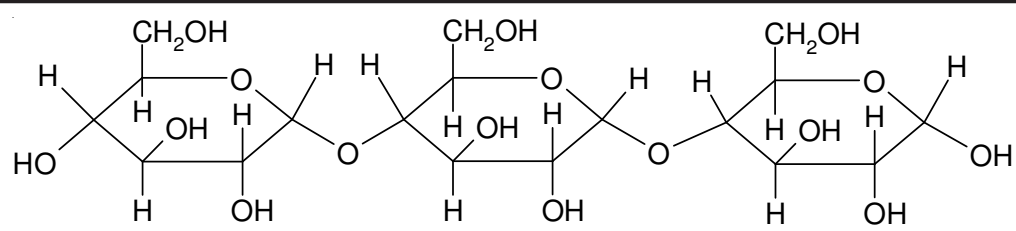

(a)

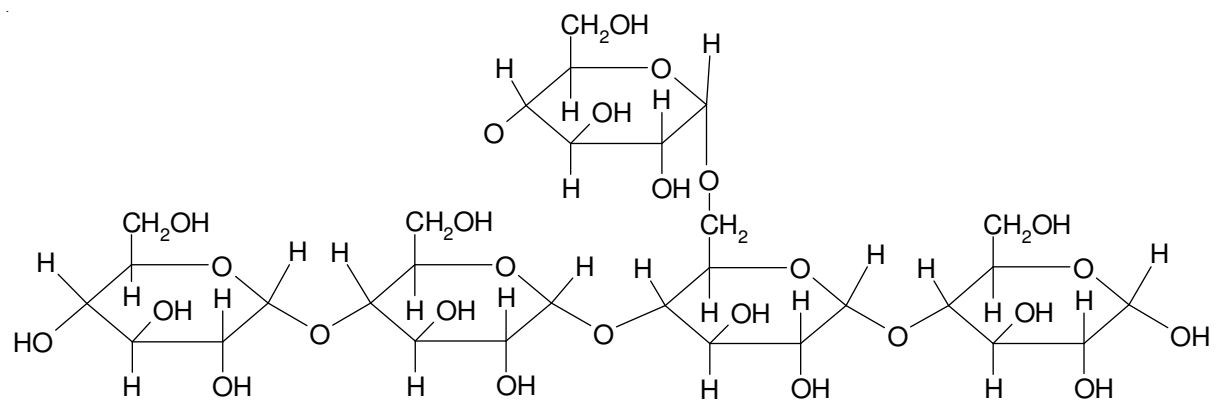

(b)

Fig. 2. (a) Linear and (b) branched structures of starch

studied $^{22}$. Rheological data showed that rheograms of all the blends lie between those of pure components over the entire compositional range, indicating that the miscibility of the blends may occur.

The experiments with polymer blends are interesting, since in industry, with variation in concentration of the polymers, with different properties, a product with some desired characteristics can be obtained. Knowledge of modification of the viscosity values produced by the utilization of polymer blends is important because of the effect that it has on the operational cost of several stages of the industrial process. It is important to know the physicochemical properties of chitosan-starch solutions as both polymers find their applications in various fields like drug delivery, wound healing, dressing materials etc. The rheological properties of solution can be adequately described by Brookfield viscometer and power law parameters (consistency coefficient and flow behaviour index). In this work, the change in behaviour of blended solution is studied when different concentrations of chitosan are added with respect to starch. To fit experimental data, power law model is used. This model is chosen for its simplicity and the good fit to the experimental data.

\section{EXPERIMENTAL}

Chitosan low viscous (loss on drying $<10 \%$ ash, Insoluble matter $>1 \%$, viscosity $<200 \mathrm{~m} \mathrm{~Pa} \mathrm{~s}$ ) was supplied by Fluka Bio Chemica (Germany) and corn starch procured from Himedia (India). Acetic acid $(99.5 \%)$ was purchased from Merck (Germany). For the preparation of solutions double distilled water was used to prepare all solutions.

Method: Chitosan has higher molecular weight as compared to starch and both polymers can not be dissolved in a common solvent due their different chemical natures. Therefore both the polymers were dissolved separately in different solvents and mixed together afterwards. Four different solutions (1-4 \%) of acetic acid in water are prepared. The solution of chitosan is prepared by dissolving a known amount of chitosan in $20 \mathrm{~mL}$ of aqueous acetic acid (1, 2, 3 and $4 \%$ ) solution at room temperature $\left(25^{\circ} \mathrm{C}\right)$, while stirring for three hours. To prepare a solution of starch a known quantity of starch is dissolved in $20 \mathrm{~mL}$ ultrapure water from Millipore synergy water system at $95^{\circ} \mathrm{C}$ heating with stirring till 20 min followed by cooling. Afterwards, both solutions of chitosan and starch are mixed together while stirring to produce a uniform blended solution and kept for $24 \mathrm{~h}$ which resulted in a bubble free and clear solution. Table-1 shows the composition for all the solutions prepared in this study. The range of concentration of both the polymers selected so as to produce compatible blends. It is observed that chitosan-starch polysaccharides are not compatible for viscosity measurement when starch concentration is more than $60 \%$ by weight.

\begin{tabular}{|c|c|c|c|}
\hline \multicolumn{4}{|c|}{$\begin{array}{c}\text { TABLE-1 } \\
\text { COMPOSITION OF CHITOSAN AND } \\
\text { STARCH BLENDED SOLUTION }\end{array}$} \\
\hline \multicolumn{2}{|c|}{ Chitosan solution } & \multicolumn{2}{|c|}{ Starch solution } \\
\hline $\mathrm{Ch}(\mathrm{g})$ & $\mathrm{AA}^{*}(\mathrm{~mL})$ & $\mathrm{St}(\mathrm{g})$ & Water $(\mathrm{mL})$ \\
\hline 0.4 & 20 & 0.6 & 20 \\
\hline 0.5 & 20 & 0.5 & 20 \\
\hline 0.6 & 20 & 0.4 & 20 \\
\hline 0.7 & 20 & 0.3 & 20 \\
\hline 0.8 & 20 & 0.2 & 20 \\
\hline 0.9 & 20 & 0.1 & 20 \\
\hline
\end{tabular}

*Percentage of acetic acid was varied from 1-4\%.

Viscosity is a measure of fluid's resistance to flow. Viscosities of pure chitosan and pure starch, chitosan-starch blends with different ratios were determined using Brookfield digital viscometer modal DV-E version 1.00. The principle of operation of the DV-E is to drive a spindle (which is immersed in test fluid) through a calibrated spring. The viscous drag of the fluid is measured by spring deflection. The viscometer was calibrated using viscosity standard fluid and accuracy was \pm $1 \%$. The viscosity and torque values are reported in centipoises (cp) and dyne $\mathrm{cm}$, respectively. The speed of spindle is fixed at 30, 50, 60,100 rpm and spindle number (1, 2, 3, 4, 5, 6 and 7) are fixed according to viscosity of the solutions. The spindle number 1 is for very low viscous solution and spindle number 7 is for highly viscous solution. 


\begin{tabular}{|c|c|c|c|c|c|}
\hline \multicolumn{6}{|c|}{$\begin{array}{l}\text { TABLE-2 } \\
\text { FLOW BEHAVIOUR INDEX (n) } \\
\text { FOR DIFFERENT COMPOSITIONS }\end{array}$} \\
\hline \multirow{2}{*}{$\begin{array}{l}\mathrm{Ch} \\
(\mathrm{g})\end{array}$} & \multirow{2}{*}{$\begin{array}{l}\text { St } \\
\text { (g) }\end{array}$} & \multicolumn{4}{|c|}{ Flow behaviour index $(\mathrm{n})$} \\
\hline & & $1 \%$ of $\mathrm{AA}$ & $2 \%$ of $\mathrm{AA}$ & $3 \%$ of $\mathrm{AA}$ & $4 \%$ of $\mathrm{AA}$ \\
\hline 0.4 & 0.6 & 0.933 & 0.595 & 0.88 & 0.551 \\
\hline 0.5 & 0.5 & 0.896 & 0.521 & 0.724 & 0.742 \\
\hline 0.6 & 0.4 & 0.773 & 0.588 & 0.728 & 0.762 \\
\hline 0.7 & 0.3 & 0.748 & 0.742 & 0.637 & 0.599 \\
\hline 0.8 & 0.2 & 0.712 & 0.764 & 0.641 & - \\
\hline 0.9 & 0.1 & 0.676 & 0.701 & - & - \\
\hline \multicolumn{6}{|c|}{$\begin{array}{c}\text { TABLE-3 } \\
\text { CONSISTENCY COEFFICIENT FOR } \\
\text { DIFFERENT COMPOSITIONS }\end{array}$} \\
\hline \multirow{2}{*}{$\begin{array}{l}\mathrm{Ch} \\
(\mathrm{g})\end{array}$} & \multirow{2}{*}{$\begin{array}{l}\mathrm{St} \\
(\mathrm{g})\end{array}$} & \multicolumn{4}{|c|}{$\log ($ consistency coefficient $)=\log (\mathrm{K})$} \\
\hline & & $1 \%$ of $\mathrm{AA}$ & $2 \%$ of $\mathrm{AA}$ & $3 \%$ of $\mathrm{AA}$ & $4 \%$ of $\mathrm{AA}$ \\
\hline 0.4 & 0.6 & -0.084 & 0.511 & 0.357 & 0.681 \\
\hline 0.5 & 0.5 & 0.616 & 0.847 & 0.657 & 0.619 \\
\hline 0.6 & 0.4 & 0.804 & 1.721 & 0.885 & 0.912 \\
\hline 0.7 & 0.3 & 1.069 & 1.199 & 1.263 & 1.768 \\
\hline 0.8 & 0.2 & 1.1111 & 1.2180 & 1.445 & - \\
\hline 0.9 & 0.1 & 1.2920 & 1.5910 & - & - \\
\hline
\end{tabular}

Density is measured with the help of pychnometer having a bulb volume of $10 \mathrm{~cm}^{3}$ and a capillary bore with an internal diameter of $1 \mathrm{~mm}$. The pycnometer was filled to specific volume with accuracy followed by the measurement of mass of solution.

The measurement of refractive index of $1 \mathrm{~g}$ polymeric sample was done by Abbes refractometer. Refractive index for sodium D-line is measured to an uncertainty of 0.0001 with thermostatically controlled refractometer. The scale is adjusted so that the boundary between light and dark coincides with the center of the cross hairs. The refractive index on the top scale in the lower part of the viewer was read and recorded of each solution.

\section{RESULTS AND DISCUSSION}

Measurement of viscosity: The viscosity is a very important physicochemical parameter in polymer processing. Viscosity of various compositions of blended solution was measured by Brookfield viscometer. The variations in viscosity with concentration of chitosan in blends are plotted in Figs. 3-6. Chitosan solution wa prepared in different concentrations of acetic acid (1-4\%) and variation in viscosity with concentration of blended solution (with $1 \%$ acetic acid) is presented in Fig. 3. It is observed that the viscosity of solution increases with increasing concentration of chitosan in blended solutionb. Chitosan has higher molecular weight as compared to starch and increase in concentration chitosan leads to increase in viscosity of blend. It is known that as the concentration of polymer increases the chains of polymer become more entangled and higher shear force is required in order to flow the solution. Further, it is observed that as the speed of rotation (rpm) of spindle increases from 30 to 100 the viscosity of solution decreases from $10.5 \times 10^{-3} \mathrm{cp}$ to $7.8 \times 10^{-3} \mathrm{cp}$ for 80 $\%$ concentration of chitosan in blended solution (in $1 \%$ acetic acid). This is due to the fact that the extent of entanglement decreases with the application of shear force and thus decrease in viscosity occurs. Similar results were observed for blends

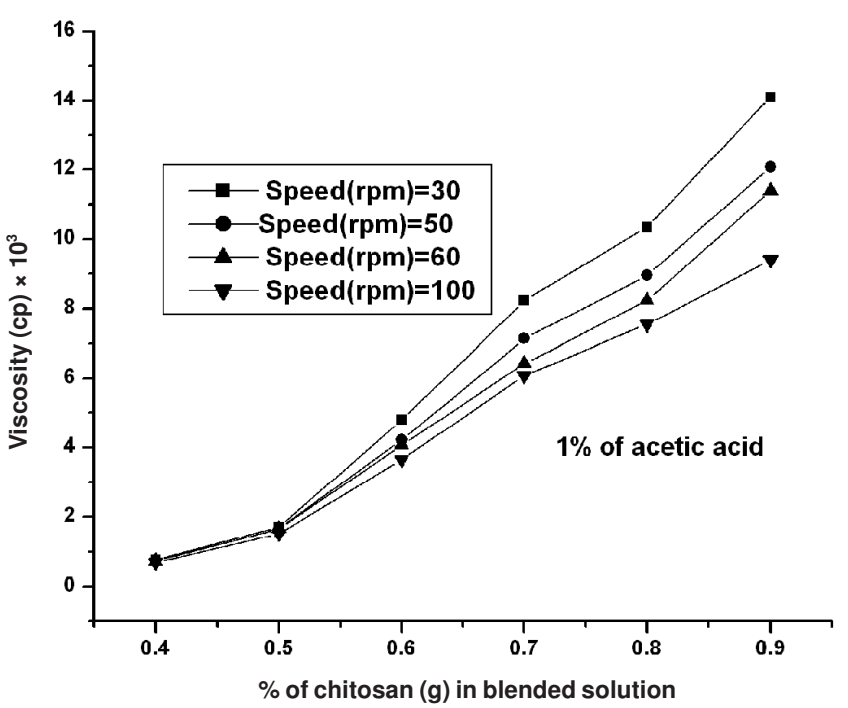

Fig. 3. $1 \%$ acetic acid (viscosity versus chitosan $(\mathrm{g}) / \mathrm{starch}(\mathrm{g})$ ) and spindle speed $100 \mathrm{rpm}, 60 \mathrm{rpm}, 50 \mathrm{rpm}, 30 \mathrm{rpm}$ at $25^{\circ} \mathrm{C}$

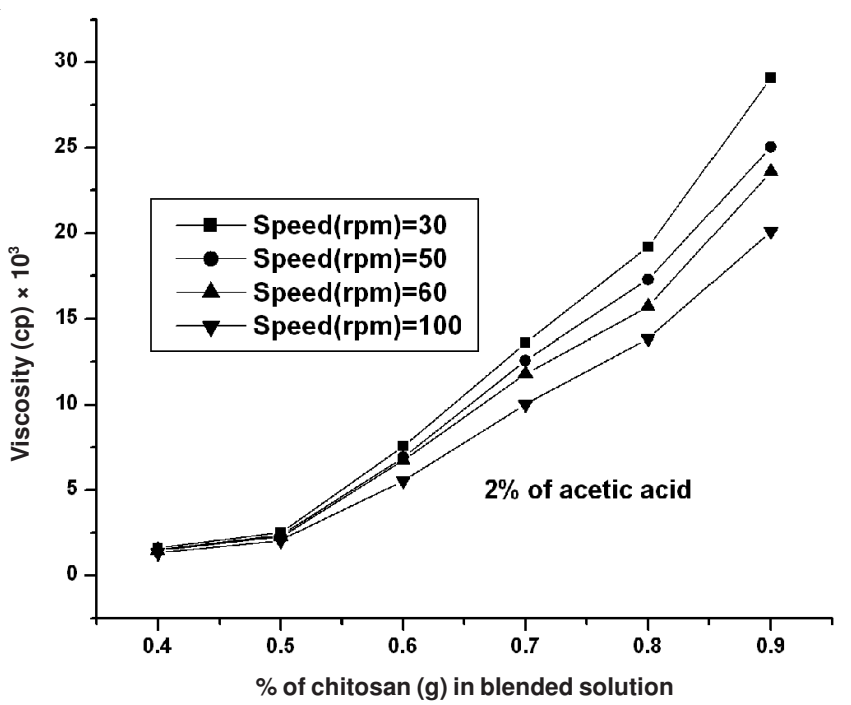

Fig. 4. $2 \%$ acetic acid (viscosity versus chitosan $(\mathrm{g}) / \mathrm{starch}(\mathrm{g})$ ) and spindle speed $100 \mathrm{rpm}, 60 \mathrm{rpm}, 50 \mathrm{rpm}, 30 \mathrm{rpm}$ at $25^{\circ} \mathrm{C}$

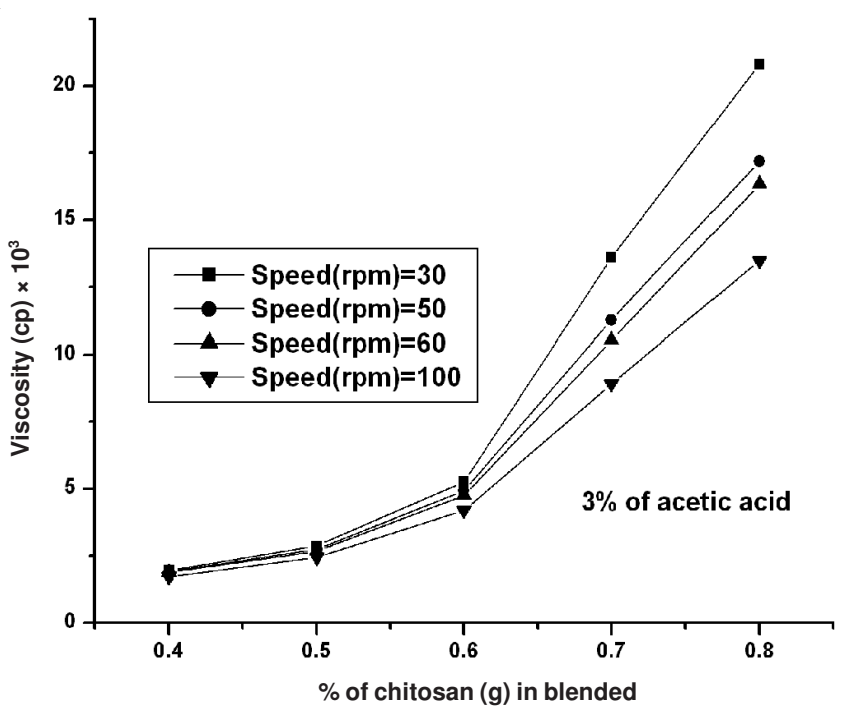

Fig. 5. $3 \%$ acetic acid (viscosity versus chitosan $(\mathrm{g}) / \mathrm{starch}(\mathrm{g})$ ) and spindle speed $100 \mathrm{rpm}, 60 \mathrm{rpm}, 50 \mathrm{rpm}, 30 \mathrm{rpm}$ at $25^{\circ} \mathrm{C}$ 


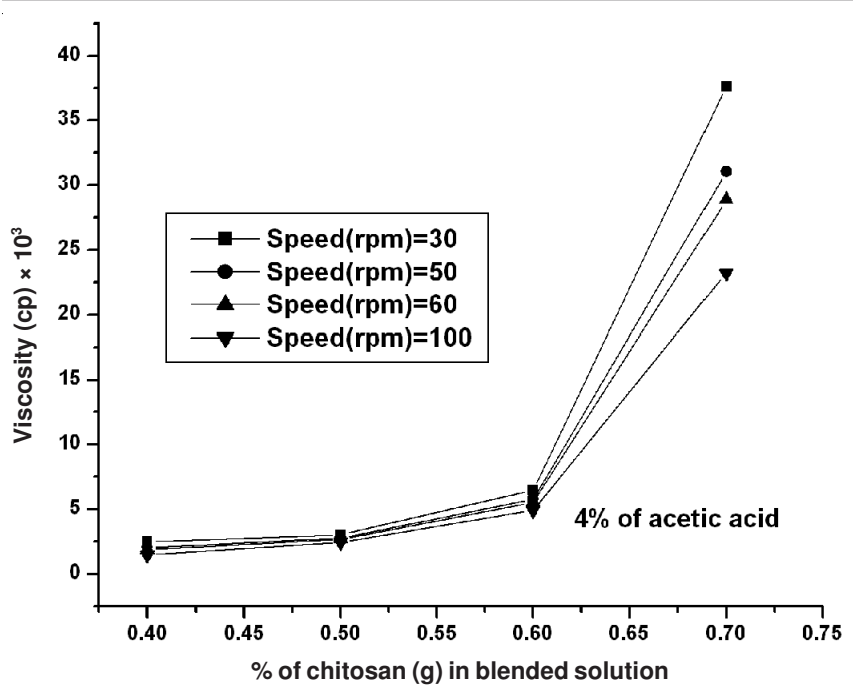

Fig. 6. $4 \%$ acetic acid (viscosity versus chitosan $(\mathrm{g}) / \mathrm{starch}(\mathrm{g}))$ and spindle speed $100 \mathrm{rpm}, 60 \mathrm{rpm}, 50 \mathrm{rpm}, 30 \mathrm{rpm}$ at $25^{\circ} \mathrm{C}$

prepared in 2, 3 and $4 \%$ acetic acid solution as shown in Figs. 4-6. It is further observed that as the concentration of acetic acid increases the viscosity of solution increases tremendously and it becomes very difficult to measure viscosity of solution having concentration more than $70 \%$ in case of solution prepared in $4 \%$ acetic acid show negligible variation in viscosity for chitosan concentration up to $50 \%$ and a slight increase in viscosity is observed as the concentration of chitosan rises to $60 \%$. With further increase in concentration of chitosan to $70 \%$ the viscosity of solution increases rapidly. Therefore, simultaneous increase in concentration of chitosan and acetic acid results into a very viscous blend of which viscosity measurement with Brookfield viscometer becomes infeasible.

Steady shear viscosity: It is observed that the flow and viscosity curves are straight lines indicating that the Ostwaldde Wale equation (Power law model) can be applied. In order to describe the steady-shear rheological properties of samples; the data was fitted to the well known Power law model.

$$
\sigma=\mathrm{Ky}^{\mathrm{n}}
$$

where $\sigma=$ shear stress $(\mathrm{Pa}) ; \mathrm{K}=$ consistency coefficient $(\mathrm{Pa}$ $\left.\mathrm{S}^{\mathrm{n}}\right) ; \mathrm{y}=$ shear rate $\left(\mathrm{S}^{-1}\right) ; \mathrm{n}=$ flow behaviour index.

$$
\eta=\frac{\sigma}{\mathrm{y}}
$$

In applying the Mitschka method, the flow behaviour index is found form the slope of the logarithm of shear stress verses logarithm of rotational speed plot $^{23}$.

$$
\mathrm{n}=\frac{\mathrm{d}\left(\log _{10} \sigma\right)}{\mathrm{d}\left(\log _{10} \mathrm{~N}\right)}
$$

where $\sigma=$ shear stress, $\mathrm{Pa}, \mathrm{N}=$ rotational speed $\mathrm{rpm}$ and $\eta$ is apparent viscosity in centipoises.

The flow behaviour index (n) and consistency coefficient are obtained by plotting graphs between $\log$ (shear stress) versus $\log$ (shear rate) for different solutions. According to Fig. 7, calculated value of $\mathrm{n}$ of $2 \%$ acetic acid (chitosan/starch as $0.4 / 0.6$ ) and $4 \%$ acetic acid (chitosan/starch as 0.4/0.6) are found to be $0.595,0.551$, respectively. These values of $n$

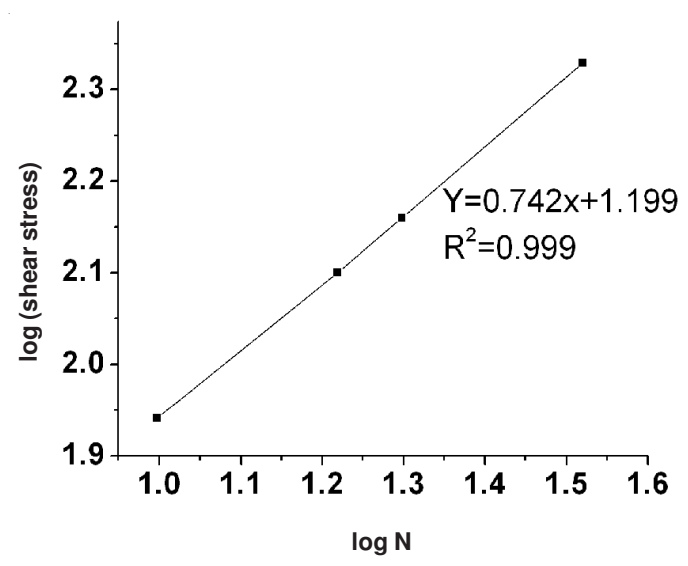

Fig. 7. Logarithm of spindle speed (N) versus logarithm of shear stress

indicated that the both solutions are highly pseudo plastic in nature to assign deviation from Newtonian behaviour due the presence of entanglements. However, solution of $1 \%$ acetic acid (chitosan/starch) approaches nearly Newtonian behaviour ( $\mathrm{n}=0.933$ ). It is observed that all the blend compositions exhibit non-Newtonian behaviour with increasing chitosan concentration.

Measurement of density: The pycnometer is an instrument used for measuring fluid density and operation of pycnometer is based on the Archimedes's principle. Only limitation in this measurement is that the viscosity of highly viscous solution cannot be measured by pycnometer. Fig. 8 shows the relationship between the density and concentration of chitosan/starch blended solution at $25 \pm 1{ }^{\circ} \mathrm{C}$. Almost a linear relationship is observed between density and concentration of chitosan in chitosan/starch blend prepared in $1 \%$ acetic acid solution. A slight change in pattern of variation of viscosity is observed and the slope of linearity increases as the concentration of acetic acid in the blended solution increases from $2-4 \%$. This variation in density is small for lower concentration of chitosan (i.e. $10 \%$ ) as compared to higher concentration of chitosan (i.e. $60 \%$ ).

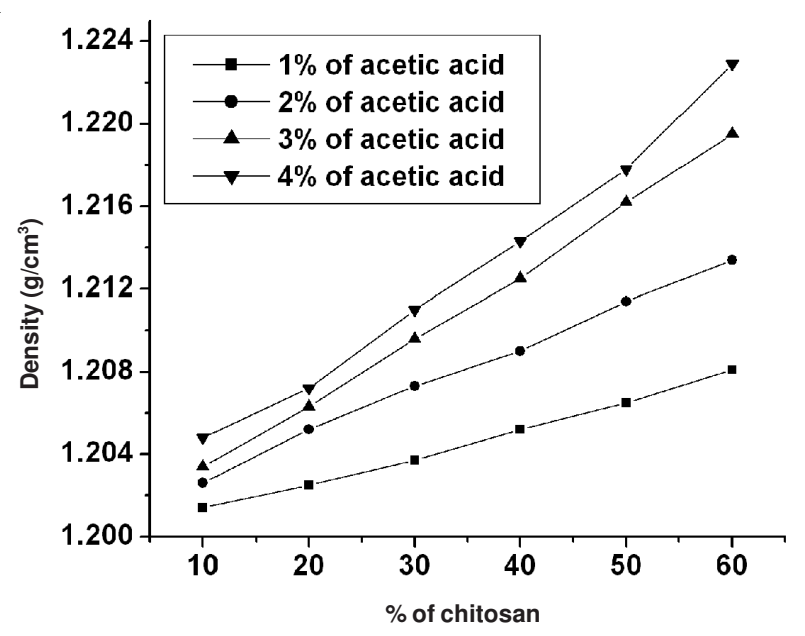

Fig. 8. Variation of density with chitosan concentration at $25^{\circ} \mathrm{C}$

Measurement of refractive index: Variation of refractive index with solution concentration is shown in Fig. 9. A linear relationhip was observed between refractive index and 


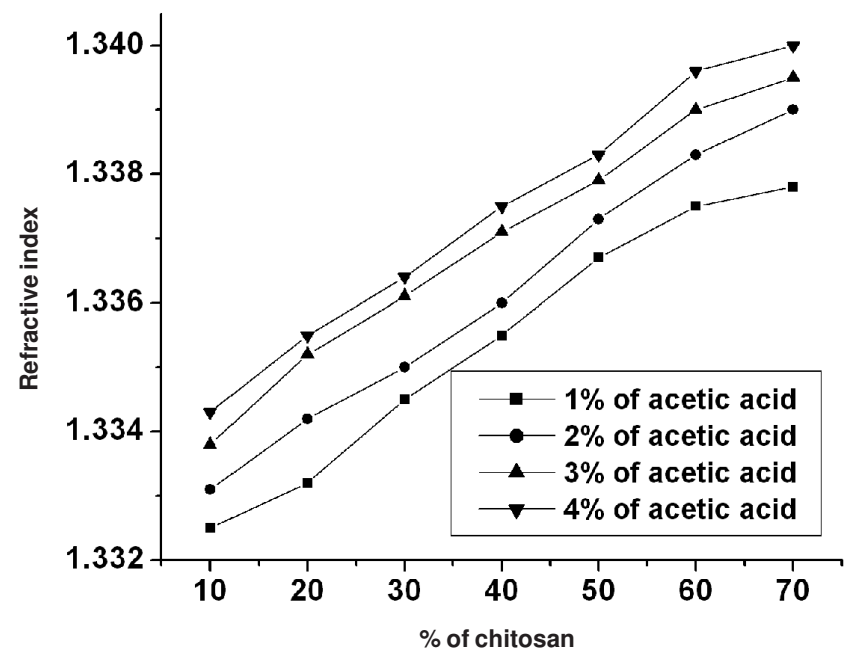

Fig. 9. Variation of Refractive index with chitosan concentration at $25^{\circ} \mathrm{C}$

concentration of chitosan in blend. A lower value of refractive index of blended solution indicated more transparent solution.

\section{Conclusion}

In this work, rheological properties of chitosan/starch blends were investigted at $25 \pm 1{ }^{\circ} \mathrm{C}$. The most important characteristic of a polymer blend of two polymers is the phase behaviour. It is observed visually that blends of chitosan and starch were miscible over the entire range of composition but, viscosity measurement with Brookfield viscometer was feasible only for chitosan concentration between 40-80\% depending up on the concentration of acetic acid. This study showed that the dynamic rheological measurement of chitosan solution in acetic acid suggested pseudo plastic non-Newtonian behaviour. Density and refractive index are other important physico-chemical parameters of polymer blends which affect the production cost and profitability of manufacturing process. This study showed that density and refractive index of chitosan/ starch blend increased with concentration of chitosan in blend.

\section{REFERENCES}

1. T.A. Sonia and C.P. Sharma, Adv. Polym. Sci., 243, 23 (2011).

2. M.N.V.R. Kumar, React. Funct. Polym., 46, 1 (2000).

3. M. Rinaudo, Prog. Polym. Sci., 31, 603 (2006).

4. L. Ammayappan and J.J. Moses, Fibers Polym., 10, 161 (2009).

5. F. Atyabi, S. Manoochehri, S.H. Moghadam and R. Dinarvand, Arch. Pharm. Res., 29, 1179 (2006).

6. G. Hamdi and G. Ponchel, Pharm. Res., 16, 867 (1990).

7. S.B. Bahrami, S.S. Kordestani, H. Mirzadeh and P. Mansoori, Iran. Polym. J., 12, 139 (2003).

8. T. Matsumoto, M. Kawai and T. Masuda, Biopolymers, 31, 1721 (1991).

9. R.H. Chen, J.H. Lin and M.H. Yang, Carbohydr. Polym., 24, 41 (1994).

10. M.L. Tsaih and R.H. Chen, J. Appl. Polym. Sci., 73, 2041 (1999).

11. H.-F. Guo, H.-L. Lin and T.L. Yu, J. Macromol. Sci. A: Pure Appl. Chem., 39A, 837 (2002).

12. R.H. Chen and M.L. Tsaih, Int. J. Biol. Macromol., 23, 135 (1998).

13. M. Rinaudo, G. Pavlov and J. Desbrieres, Polymer, 40, 7029 (1999).

14. K. Kurita, Prog. Polym. Sci, 26, 1921 (2001).

15. S. Aiba, Int. J. Biol. Macromol, 13, 40 (1991).

16. N. Kubota and Y. Eguchi, Polym. J., 29, 123 (1997).

17. S. Zivanovic, J. Li, P.M. Davidson and K. Kit, Biomacromolecules, 8 , 1505 (2007).

18. J. Bergera, M. Reista, J.M. Mayera, O. Felt and R. Gurny, Eur. J. Pharm. Biopharm., 57, 35 (2004).

19. Y. Hülya and B. Ceyhun, J. Polym. Environ., 11, 107 (2003).

20. M.D. Kurkuri, A.R. Kulkarni and M. Aminabhavi, J. Appl. Polym. Sci., 86, 526 (2002).

21. C. Elvira, J.F. Mano, J. San Roman and R.L. Reis, Biomaterials, 2, 1955 (2002).

22. R.K. Wanchoo, A. Thakur and Sweta, Chem. Biochem. Eng. Q, 22, 15 (2008).

23. P. Mitschka, Rheol. Acta, 21, 207 (1982). 